\section{Hypomelanosis of Ito: A Rare Disorder with Rarer Presentation-Unilateral Retinal Detachment and Bilateral Glaucoma}

\author{
Kanika Jain ${ }^{1 *}$, Manav D Singh ${ }^{2}$ and Harshika Chawla ${ }^{3}$ \\ ${ }^{1}$ Senior Resident, Department of Ophthalmology, Deen Dayal Upadhyay \\ Hospital, Delhi, India
}

${ }^{2}$ Department of Ophthalmology PGIMER, Dr. R.M.L Hospital, Delhi, India

${ }^{3}$ Senior Resident, Department of Ophthalmology, Nirmal Ashram Eye Institute, Rishikesh, India

\begin{abstract}
Hypomelanosis of Ito, also known as Hypomelanosis of Achromia, Incontenentia pigmenti Achromians, pigmentary dysplasia or mosaicism, is a rare dermatological disease with a prevalence of 1 in 8000-10,000 live births predominantly affecting females. Disease is usually sporadic but familial cases have been reported. It is characterized by streaked/ whorled patches of light colored skin. It may have neurological abnormalities (seizures being the most common), dental abnormalities (defective teeth implantation, cortical teeth, partial anodontia/hypodontia) and ophthalmic associations like strabismus. We hereby report a case of a 13 years old female having Hypomelanosis of Ito with bilateral cataract and angle closure glaucoma complicated with unilateral retinal detachment which are rare associations. She underwent a cataract surgery as well as implantation of Glaucoma Drainage Device (GDD) in the right eye after a failed trabeculectomy.
\end{abstract}

Keywords: Angle closure glaucoma; Cataract; Hypomelanosis of Ito, Incontinentia pigmenti achromians; Retinal detachment

\section{Introduction}

Hypomelanosis of Ito, also known as Hypomelanosis of Achromia, Incontenentia pigmenti Achromians, pigmentary dysplasia

*Corresponding author: Kanika Jain, Senior Resident, Department of Ophthalmology, Deen Dayal Upadhyay Hospital, Delhi, India, E-mail: kanikajain024@gmail.com

Citation: Jain K, Singh MD, Chawla H (2020) Hypomelanosis of Ito: A Rare Disorder with Rarer Presentation-Unilateral Retinal Detachment and Bilateral Glaucoma. J Ophthalmic Clin Res 7: 074.

Received: December 22, 2020; Accepted: December 28, 2020; Published: December 31, 2020

Copyright: ( 2020 Jain K, et al. This is an open-access article distributed under the terms of the Creative Commons Attribution License, which permits unrestricted use, distribution, and reproduction in any medium, provided the original author and source are credited. or mosaicism, is a rare dermatological disease with a prevalence of 1 in $8000-10,000$ live births predominantly affecting females. Disease is usually sporadic but familial cases have been reported. It is characterized by streaked/ whorled patches of light colored skin. It may have neurological abnormalities (seizures being the most common), dental abnormalities (defective teeth implantation, cortical teeth, partial anodontia/hypodontia) and ophthalmic associations like strabismus [1-4]. Management of these cases is a multidisciplinary approach. We report a case of a 13 years old female having Hypomelanosis of Ito associated with bilateral cataract and angle closure glaucoma complicated by unilateral retinal detachment which are rare associations. She underwent a cataract surgery as well as implantation of Glaucoma Drainage Device (GDD) in the right eye after a failed trabeculectomy.

\section{Case Report}

A 13 years old female presented to our hospital in 2015 with complaints of sudden painful diminution of vision in left eye since the past one month. She had a history of recurrent episodes of left sided headache with nausea-about 5-6 such episodes per month over the past 1 year. These episodes were usually associated with diminution of vision in left eye and were relieved by taking analgesics or sleeping. Systemic, birth, family or personal history was non contributory. There was no history of any prolonged intake of steroids in any form (oral/topical/inhalational).

Upon clinical evaluation, hypopigmented streaks were present on both upper extremities (Figure 1a) along with scattered patches of alopecia over scalp (Figure 1b). She also had microdontic, abnormally shaped teeth along with polydactyly and syndactyly in left foot (Figure 1c).

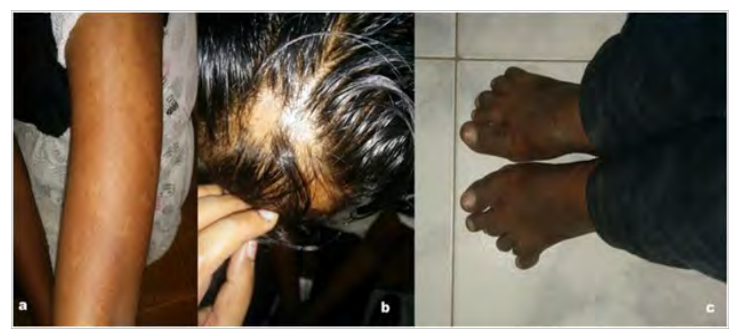

Figure 1: Clinical photograph of the patient showing a) Hypopigmented patches/streaks on the skin of the arm, b) Alopecia patches on the scalp, c) Polydactyly and syndactyly of $2^{\text {nd }}$ and $3^{\text {rd }}$ toes as well as $5^{\text {th }}$ and $6^{\text {th }}$ toes of the left foot.

On ophthalmic evaluation, Best Corrected Visual Acuity (BCVA) was $6 / 24$ in right eye and perception of light with inaccurate projection of rays in left eye. Horizontal nystagmus was present in both eyes. Iris was normal in color and pattern in right eye. However, left eye had Neovascularisation of Iris (NVI) with partial loss of pupillary ruff (Figure 2). Relative Afferent Pupillary Defect (RAPD) was noted in left eye. Cortical cataract as well as posterior subcapsular 
Citation: Jain K, Singh MD, Chawla H (2020) Hypomelanosis of Ito: A Rare Disorder with Rarer Presentation-Unilateral Retinal Detachment and Bilateral Glaucoma. J Ophthalmic Clin Res 7: 074.

cataract with diffuse pigment deposition on anterior lens capsule was observed in both eyes (Figure 2). Intraocular Pressures (IOP) as measured by Goldmann Applanation Tonometry were 43 and $6 \mathrm{~mm}$ $\mathrm{Hg}$ in right eye and left eye respectively. Central corneal thickness by ultrasonic pachymetry was 635 and $645 \mu \mathrm{m}$ in right eye and left eye respectively. On gonioscopy, occludable angles were seen in Right Eye with steep iris configuration (Figure 3a) and angles were closed in left eye with 360 degrees Peripheral Anterior Synechiae (PAS) (Figure 3b). Fundus of RE showed tilted disc with cup to disc ratio of 0.6-0.7:1 and peripapillary hypopigmented streaks (Figure 4a). Total retinal detachment was seen in left eye which was also confirmed by Ultrasound B scan (Figure 4b).

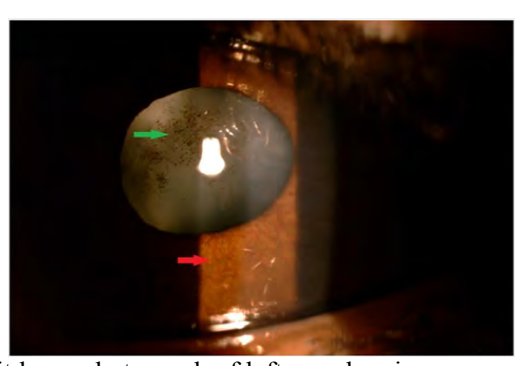

Figure 2: Slit lamp photograph of left eye showing neovascularisation of iris at 6 o'clock position (red arrow) with cataract and pigmentation on anterior lens capsule (green arrow).

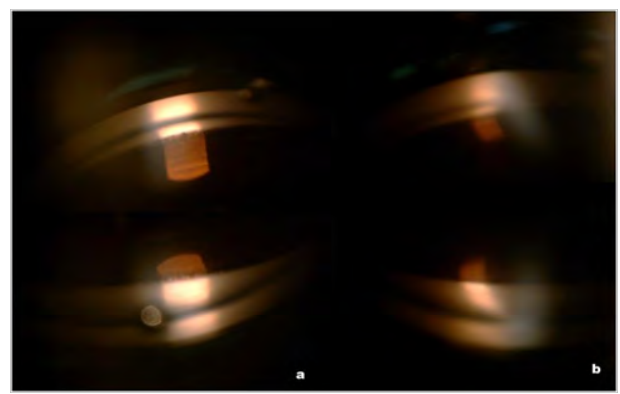

Figure 3: Slit lamp photograph showing gonioscopy photograph of a) right eye showing occludable angles with excessive trabecular pigmentation for age and steep iris configuration, b) left eye showing closed angles360 Peripheral Anterior Synechiae (PAS).

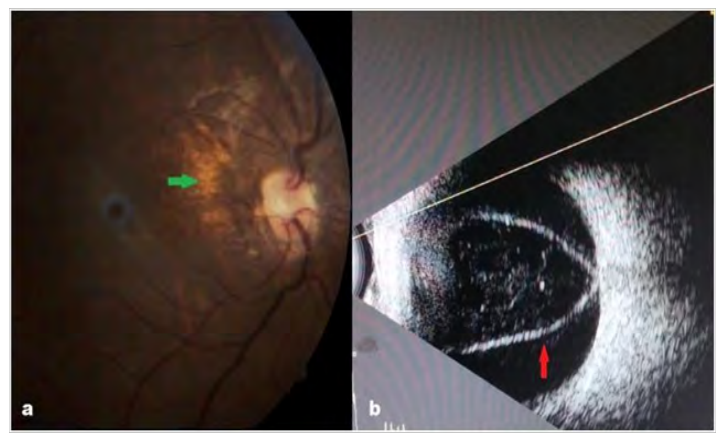

Figure 4: a) Fundus photograph of right eye showing tilted disc with cup disc ratio of 0.6-0.7:1 and peripapillary hypopigmented streaks (green arrow), b) Ultrasound B scan of left eye showing membrane attached to the optic nerve suggestive of retinal detachment (red arrow).
On the basis of above typical dermatologic and dental findings, she was diagnosed as a case of Hypomelanosis of Ito by dermatologist and paediatrician. Vitreoretinal surgery in left eye was avoided in view of poor visual prognosis. The patient underwent right eye phacoemulsification with intraocular lens implantation under general anesthesia. Cataract surgery was done for quick visual rehabilitation and combined surgery was avoided in view of patient being one eyed. Since, IOP was uncontrolled in right eye despite maximum medical therapy; the patient underwent trabeculectomy with $0.2 \%$ Mitomycin $\mathrm{C}$ under general anesthesia 3 months post her cataract surgery. The postoperative period was uneventful although IOP was still uncontrolled with a failed trabeculectomy, so the patient was advised GDD (Ahmed Glaucoma Valve-FP7 variant) implantation along with a scleral patch graft which she underwent 5 months post her trabeculectomy. Postoperatively, at the time of her 4 years follow up, her IOP was well controlled $(14 \mathrm{~mm}$ of $\mathrm{Hg}$ on 2 antiglaucoma medications, with well formed bleb and a patent GDD tube in anterior chamber) and BCVA of 6/9 in right eye.

Appropriate genetic counseling along with evaluation of other siblings was undertaken although all the other siblings and parents were asymptomatic. Patient was advised to be on regular follow up every 6 monthly.

\section{Discussion}

Hypomelanosis of Ito is a rare dermatological disease with a reported prevalence of 1 in 8000-10,000 and it predominantly affects females. Disease is usually sporadic but familial cases have also been reported with inheritance patterns being autosomal dominant, autosomal recessive as well as $\mathrm{X}$ linked. Its cause is unknown and various chromosomal abnormalities have been identified on chromosomes- 9q33, 15q11-q13, Xp11, X p21.2 [1,2]. However, in many patients the condition arises from genetic irregularities that are present in some cells of the body, but not in others (mosaicism). Some researchers believe that it does not represent a distinct disorder but rather a symptom, common to a group of disorders involving genetic mosaicism [5]. It is characterized by dermatologic manifestations include changes in hair color, diffuse alopecia on scalp, trichorrhexis nodosa, polydactyly, coarse facial features. Hypomelanosis may present as hypopigmented patches, streaks or whorled areas in any part of the body. The skin lesions usually appear during the first year of life and remain unchanged through childhood, but may fade or darken in adulthood. Skin lesions are not associated with inflammation or a premalignancy. Neurological findings such as infantile seizures resistant to therapy, cognitive impairment, developmental delays and musculoskeletal symptoms such as scoliosis are commonly associated with this condition. Dental manifestations include defective implantation, cortical teeth, partial anodontia, hypodontia [3-6]. The symptoms usually become apparent during the first or second year of life. Ophthalmic associations can be variable like strabismus, aplasia/hypoplasia of iris, heterochromia iridis, corneal opacity, hypertelorism, myopia, uveal coloboma or microphthalmos. Rare ophthalmic associations include nystagmus and cataract $[3,4]$. Presence of bilateral cataract in this condition is very rare as was seen in our case. Furthermore, we did not find any reported association of glaucoma with this condition. Thus ours is a rare case of Hypomelanosis of Ito which was diagnosed on the basis of characteristic clinical features, with bilateral angle closure glaucoma and cataract and unilateral retinal detachment. However, we did share same findings like cataract and retinal detachment with a previous 
reported case [7] although this patient had cataract in one eye and retinal detachment in the contralateral eye. Another case report of a 4 month female baby with incontinenti pigmenti had ophthalmic features in the form of bilateral retinal detachment is also documented [8].

We believe that the chronically raised IOP $(>40 \mathrm{~mm}$ of $\mathrm{Hg})$ in the left eye lead to traction on the retina leading to retinal detachment and also the chronic ischaemia due to raised IOP lead to NVI. There was no similar history in family or in other siblings thus highlighting that there was a sporadic mutation affecting our patient.

This case highlights the importance of a good general physical examination, especially in cases with atypical findings. Patients with Hypomelanosis of Ito should be investigated for associated sightthreatening ocular pathologies to prevent visual morbidity.

\section{Conclusion}

This case highlights the importance of a good general physical examination, especially in cases with atypical findings. Appropriate referrals to paediatrician/dermatologist should be done when faced with atypical features in clinical practice. Patients with Hypomelanosis of Ito should be investigated for associated sight-threatening ocular pathologies. It also highlights the role of an ophthalmologist among these patients because timely and appropriate management can significantly reduce visual morbidity. An inquisitive mind with detailed systemic evaluation is required on part of ophthalmologist to reach a correct diagnosis in cases of unusual ophthalmic findings.

\section{References}

1. Incontinentia Pigmenti Achromians. Medline Plus, USA.

2. Vergine G (2008) Ito Hypomelanosis. Orphanet.

3. Ruiz-Maldonado R, Toussaint S, Tomayo L, Laterza A, Del Castillov (1992) Hypomelanosis of Ito: diagnostic criteria and report of 41 cases. Pediatr Dermatol 9: 1-10.

4. Glover MT, Brett EM, Atherton DJ (1989) Hypomelanosis of Ito: Spectrum of the disease. J Pediatr 115: 75-80.

5. Valdebran M, Wright TS (2018) Hypomelanosis of Ito: Background, Pathophysology, Etiology, New York, USA.

6. Boissy RE (2015) Hypomelanosis of Ito. Rare Disease Database, NORD (National Foundation for Rare Disorders), Washington, D.C., USA.

7. Weaver RG Jr, Martin T, Zanolli MD (1991) The ocular changes of incontinentia pigmenti achromians (Hypomelanosis of Ito). J Pediatr Ophthalmol Strabismus 28: 160-163.

8. Emre S, Firat Y, Güngör S, Firat AK, Karincaoğlu Y (2009) Incontinentia pigmenti: A case report and literature review. Turk J Pediatr 51: 190-194. 


\section{di \\ нетар}

Advances In Industrial Biotechnology | ISSN: 2639-5665

Advances In Microbiology Research | ISSN: 2689-694X

Archives Of Surgery And Surgical Education | ISSN: 2689-3126

Archives Of Urology

Archives Of Zoological Studies | ISSN: 2640-7779

Current Trends Medical And Biological Engineering

International Journal Of Case Reports And Therapeutic Studies | ISSN: 2689-310X

Journal Of Addiction \& Addictive Disorders | ISSN: 2578-7276

Journal Of Agronomy \& Agricultural Science | ISSN: 2689-8292

Journal Of AIDS Clinical Research \& STDs | ISSN: 2572-7370

Journal Of Alcoholism Drug Abuse \& Substance Dependence | ISSN: 2572-9594

Journal Of Allergy Disorders \& Therapy | ISSN: 2470-749X

Journal Of Alternative Complementary \& Integrative Medicine | ISSN: 2470-7562

Journal Of Alzheimers \& Neurodegenerative Diseases | ISSN: 2572-9608

Journal Of Anesthesia \& Clinical Care | ISSN: 2378-8879

Journal Of Angiology \& Vascular Surgery | ISSN: 2572-7397

Journal Of Animal Research \& Veterinary Science | ISSN: 2639-3751

Journal Of Aquaculture \& Fisheries | ISSN: 2576-5523

Journal Of Atmospheric \& Earth Sciences | ISSN: 2689-8780

Journal Of Biotech Research \& Biochemistry

Journal Of Brain \& Neuroscience Research

Journal Of Cancer Biology \& Treatment | ISSN: 2470-7546

Journal Of Cardiology Study \& Research | ISSN: 2640-768X

Journal Of Cell Biology \& Cell Metabolism | ISSN: 2381-1943

Journal Of Clinical Dermatology \& Therapy | ISSN: 2378-8771

Journal Of Clinical Immunology \& Immunotherapy | ISSN: 2378-8844

Journal Of Clinical Studies \& Medical Case Reports | ISSN: 2378-8801

Journal Of Community Medicine \& Public Health Care | ISSN: 2381-1978

Journal Of Cytology \& Tissue Biology | ISSN: 2378-9107

Journal Of Dairy Research \& Technology | ISSN: 2688-9315

Journal Of Dentistry Oral Health \& Cosmesis | ISSN: 2473-6783

Journal Of Diabetes \& Metabolic Disorders | ISSN: 2381-201X

Journal Of Emergency Medicine Trauma \& Surgical Care | ISSN: 2378-8798

Journal Of Environmental Science Current Research | ISSN: 2643-5020

Journal Of Food Science \& Nutrition | ISSN: 2470-1076

Journal Of Forensic Legal \& Investigative Sciences | ISSN: 2473-733X

Journal Of Gastroenterology \& Hepatology Research | ISSN: 2574-2566
Journal Of Genetics \& Genomic Sciences | ISSN: 2574-2485

Journal Of Gerontology \& Geriatric Medicine | ISSN: 2381-8662

Journal Of Hematology Blood Transfusion \& Disorders | ISSN: 2572-2999

Journal Of Hospice \& Palliative Medical Care

Journal Of Human Endocrinology | ISSN: 2572-9640

Journal Of Infectious \& Non Infectious Diseases | ISSN: 2381-8654

Journal Of Internal Medicine \& Primary Healthcare | ISSN: 2574-2493

Journal Of Light \& Laser Current Trends

Journal Of Medicine Study \& Research | ISSN: 2639-5657

Journal Of Modern Chemical Sciences

Journal Of Nanotechnology Nanomedicine \& Nanobiotechnology | ISSN: 2381-2044

Journal Of Neonatology \& Clinical Pediatrics | ISSN: 2378-878X

Journal Of Nephrology \& Renal Therapy | ISSN: 2473-7313

Journal Of Non Invasive Vascular Investigation | ISSN: 2572-7400

Journal Of Nuclear Medicine Radiology \& Radiation Therapy | ISSN: 2572-7419

Journal Of Obesity \& Weight Loss | ISSN: 2473-7372

Journal Of Ophthalmology \& Clinical Research | ISSN: 2378-8887

Journal Of Orthopedic Research \& Physiotherapy | ISSN: 2381-2052

Journal Of Otolaryngology Head \& Neck Surgery | ISSN: 2573-010X

Journal Of Pathology Clinical \& Medical Research

Journal Of Pharmacology Pharmaceutics \& Pharmacovigilance | ISSN: 2639-5649

Journal Of Physical Medicine Rehabilitation \& Disabilities | ISSN: 2381-8670

Journal Of Plant Science Current Research | ISSN: 2639-3743

Journal Of Practical \& Professional Nursing | ISSN: 2639-5681

Journal Of Protein Research \& Bioinformatics

Journal Of Psychiatry Depression \& Anxiety | ISSN: 2573-0150

Journal Of Pulmonary Medicine \& Respiratory Research | ISSN: 2573-0177

Journal Of Reproductive Medicine Gynaecology \& Obstetrics | ISSN: 2574-2574

Journal Of Stem Cells Research Development \& Therapy | ISSN: 2381-2060

Journal Of Surgery Current Trends \& Innovations | ISSN: 2578-7284

Journal Of Toxicology Current Research | ISSN: 2639-3735

Journal Of Translational Science And Research

Journal Of Vaccines Research \& Vaccination | ISSN: 2573-0193

Journal Of Virology \& Antivirals

Sports Medicine And Injury Care Journal | ISSN: 2689-8829

Trends In Anatomy \& Physiology | ISSN: 2640-7752

Submit Your Manuscript: https://www.heraldopenaccess.us/submit-manuscript 